\title{
Bio-analytical chiral chromatography method for the enantioselective separation of carbinoxamine maleate in human plasma
}

\author{
Sirisha Tadiboyina*, B. M. Gurupadayya and Bharath Kumar Inturi
}

\begin{abstract}
Background: A selective chiral high-performance liquid chromatography (HPLC) method was developed and validated to separate and quantify the (d) and (I) carbinoxamine enantiomers in human plasma.

Methods: Plasma samples were extracted by liquid-liquid extraction. The separation of carbinoxamine enantiomers and internal standard (IS, pargeverine hydrochloride) was achieved on an amylose tris(5-chloro-2-methylphenylcarbamate) column with a mobile phase of n-Hexane/isopropanol/ethanol/diethyl amine (850:75:75:0.1, v/V/V/V) at a flow rate of $0.8 \mathrm{~mL} / \mathrm{min}$. The ultraviolet (UV) detection wavelength was set at $220 \mathrm{~nm}$.

Results: Baseline separation of carbinoxamine enantiomers and IS, free from endogenous interferences, was achieved in less than 15 min. Ratio of peak area of each enantiomer to IS was used for quantification of plasma samples. Linear calibration curves were obtained over the range of $20-7500 \mathrm{~g} / \mathrm{mL}$ in plasma for both enantiomers $\left(R^{2}>0.99\right)$. The mean extraction recoveries were $103.8 \pm 1.5$ and $94.5 \pm 1.8 \%$ for (d) and (I) enantiomers of carbinoxamine enantiomers and $96.35 \%$ for IS from human plasma. The mean relative error (RE \%) of accuracy and the mean relative standard deviation (RSD \%) of intra-day and inter-day precision for both enantiomers were $<10 \%$.

Conclusions: The method was validated with accuracy, precision, recovery, and stability and can be used to determine the pharmacokinetics of carbinoxamine enantiomers in human plasma.
\end{abstract}

Keywords: Chiral chromatography, Carbinoxamine enantiomers and human plasma

\section{Background}

In the pharmaceutical industry, enantiomeric separation has become an important area of study as the singleenantiomer drugs are found to be safer than racemic drugs (Pharma Book 2009). Carbinoxamine (CA) is an oral antihistamine agent that acts primarily by competing with the histamine in binding to $\mathrm{H}_{1}$ receptor. It is used as monotherapy or in combination with pseudoephedrine (or) paracetamol in the management of hay fever and allergic conjunctivitis. It is also has anticholinergic properties, and because of which, it is used in the treatment of Parkinson's disease. The chemical structure of CA was shown in Fig. 1, with one chiral center attached with pyridyl ring and chlorphenyl ring. It is

* Correspondence: tadiboyina.sirisha@gmail.com

JSS College of Pharmacy, Mysuru, Karnataka, India commercially available as the maleic acid salt (River's Edge 2011). Investigations have shown that CA was used as the racemic mixture clinically.

Ethanolamine class of $\mathrm{H}_{1}$ antihistamines were proven to show stereoselectivity in binding to the receptors (Casy et al. 1992). Doxylamine which is a similar kind of molecule to that of carbinoxamine showed that its (d) or (+) form has more binding affinity compared to its antipode (Tadiboyina et al. 2015). It is currently unclear whether CA enantiomers also possess different pharmacodynamics, toxicological, or pharmacokinetic properties. To determine the pharmacokinetic properties of CA enantiomers in vivo, it is necessary to establish a reliable method for the detection of CA enantiomers in biological samples. Table 1 shows some methods for determination of racemic CA in biological fluids and dosage forms. So 


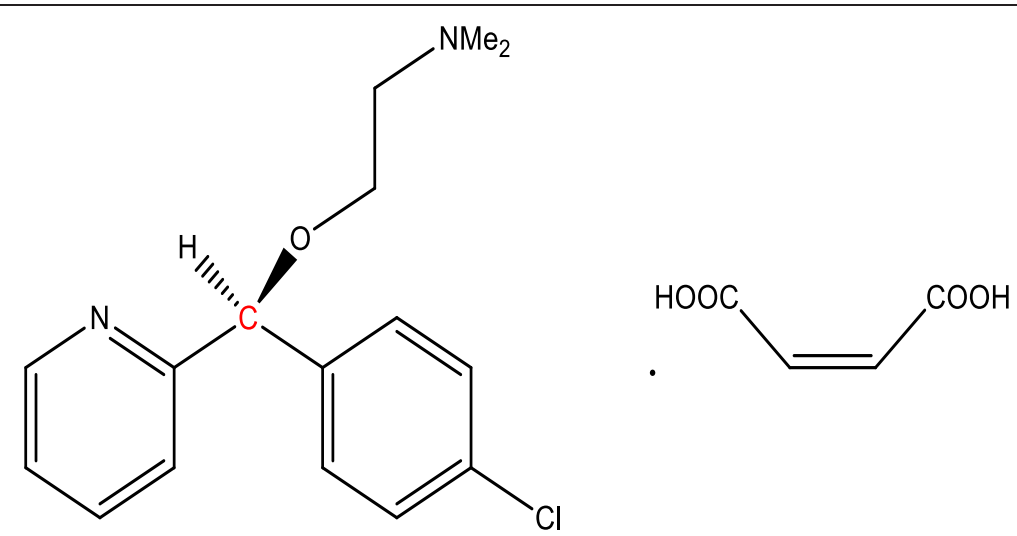

Fig. 1 Chemical structure of carbinoxamine maleate

far, very few studies were carried out to separate carbinoxamine into its individual enantiomers. Yi-Fen et al. (2000) developed a quantitative chiral analysis of carbinoxamine, doxylamine, and orphenadrine by capillary zone electrophoresis, but the method is not validated and not applied for bio-analytical studies. Therefore, it is unknown whether this method provides sufficient sensitivity and selectivity for bio-analytical studies. To our knowledge, no enantioselective methods have been developed for the determination of CA enantiomers in biological samples using a polysaccharide-based chiral column. In this paper, we describe the development of a stereoselective method for $\mathrm{CA}$ in the presence of internal standard pargeverine hydrochloride (PGV) (Fig. 2) by the normal phase method. Stationary phase was selected on the basis of functional groups present in the compound; mobile phase composition was systemically studied and finally optimized the method conditions by using eco-friendly solvents.

Table 1 Methods for the determination of CA in biological fluids and dosage forms

\begin{tabular}{|c|c|c|c|c|}
\hline Method & Conditions & Detection system & Matrices & References \\
\hline LC-MS/MS & $\begin{array}{l}\text { BDS Hypersil } C_{8}(100 \times 4.6) \text { column; } \\
\text { mobile phase: acetonitrile:buffer }(80: 20 \mathrm{~V} / \mathrm{v}) \text {; } \\
\text { buffer ( } 25 \mathrm{mM} \text { ammonium formate) }\end{array}$ & $\begin{array}{l}\text { MRM mode, } \\
\text { electrospray- } \\
\text { positive ionization }\end{array}$ & Human plasma & (GeetaBhavani et al. 2014) \\
\hline LC-MS/MS & $\begin{array}{l}\text { Waters PVA-Sil HPLC }(50 \times 4.0) \text { mm column; } \\
\text { acetonitrile:ethylacetate:water:methanol: } \\
\text { formic acid:morpholine } \\
(500: 200: 100: 60: 0.2: 0.025 \mathrm{v} / \mathrm{V} / \mathrm{V} / \mathrm{V})\end{array}$ & $\begin{array}{l}\text { Sciex API } 4000, \\
\text { triple quadrupole } \\
\text { mass spectrometer }\end{array}$ & Human plasma & (Michael et al. 2008) \\
\hline $\begin{array}{l}\text { lon exchange } \\
\text { chromatography }\end{array}$ & Column bed:carboxymethylcellulose & $\begin{array}{l}\text { Absorbance at } \\
264 \mathrm{m \mu}\end{array}$ & $\begin{array}{l}\text { Pharmaceutical } \\
\text { formulations (syrups, } \\
\text { drops, and tablets) }\end{array}$ & (Ramadan and Mandil 2006) \\
\hline \multirow[t]{2}{*}{$\begin{array}{l}\text { Spectrophotometry } \\
\text { and HPLC }\end{array}$} & $\begin{array}{l}\text { ACE } C_{18}(250 \times 4.6 \mathrm{~mm}) \text { column; mobile } \\
\text { phase: gradient elution program }\end{array}$ & \multirow{2}{*}{$\begin{array}{l}\text { DAD detection, } \\
\text { absorbance at } \\
210-300 \mathrm{~nm} \text { range }\end{array}$} & \multirow[t]{2}{*}{$\begin{array}{l}\text { Pharmaceutical } \\
\text { formulations (capsule) }\end{array}$} & \multirow[t]{2}{*}{ (Ismail and Feyyaz 2012) } \\
\hline & Acetonitrile, 0.01 sodium perchlorate $(\mathrm{pH} 3)$ & & & \\
\hline DPP and DCP & $\begin{array}{l}\text { Mobile phase: phosphate buffer (pH 1.69) using } \\
\text { dropping mercury electrode (DME) vs. Ag/Agcl }\end{array}$ & $\begin{array}{l}\text { Diffusion currents } \\
\text { (id) and peak } \\
\text { currents (ip) }\end{array}$ & $\begin{array}{l}\text { Pharmaceutical } \\
\text { formulations (tablets, } \\
\text { capsules, syrups, and } \\
\text { oral drops) }\end{array}$ & (Abdul et al. 2009) \\
\hline $\begin{array}{l}\text { lon pair reverse } \\
\text { phase high-performance } \\
\text { liquid chromatography }\end{array}$ & $\begin{array}{l}\text { C18 }(300 \times 3.9 \mathrm{~mm}) \text {; mobile phase: methanol: } \\
\text { monobasic phosphate buffer }(60: 40 \mathrm{v} / \mathrm{v}) \text { with } \\
1 \mathrm{ml} \text { phosphoric acid, } 0.5 \mathrm{ml} \text { TEA and } 0.25 \mathrm{~g} \\
\text { sodium lauryl sulfate }\end{array}$ & $\begin{array}{l}\text { UV detection } \\
300 \mathrm{~nm}\end{array}$ & $\begin{array}{l}\text { Pharmaceutical } \\
\text { formulations (tablets) }\end{array}$ & (de Carina and Marcone 2009) \\
\hline Perchloric acid titration & $\begin{array}{l}\text { Titrate: } 0.1 \mathrm{~N} \text { perchloric acid with crystal violet } \\
\text { TS as indicator }\end{array}$ & $\begin{array}{l}\text { Blue-green end } \\
\text { point }\end{array}$ & Bulk drug & (USP29-NF24 2007) \\
\hline $\begin{array}{l}\text { Capillary zone } \\
\text { electrophoresis }\end{array}$ & $\begin{array}{l}\text { Pre-column dervetization using sulfated } \\
\text { beta-cyclodextrin as a chiral selector; mobile } \\
\text { phase: tris buffer (100 mM pH 4.6) }\end{array}$ & $\begin{array}{l}\text { UV detection } \\
200 \mathrm{~nm} \text { (anode at } \\
\text { detection side) }\end{array}$ & Bulk drug & (Yi-Fen et al. 2000) \\
\hline HPLC & $\begin{array}{l}\text { Amylose-based chiral column }(250 \times 4.6 \mathrm{~mm}) \text {; } \\
\text { mobile phase: hexane:ethanol }(90: 10 \mathrm{v} / \mathrm{v})\end{array}$ & $\begin{array}{l}\text { UV detection } \\
220 \mathrm{~nm}\left(22^{\circ} \mathrm{C}\right)\end{array}$ & Bulk drug & (Phenomenex 2013) \\
\hline
\end{tabular}




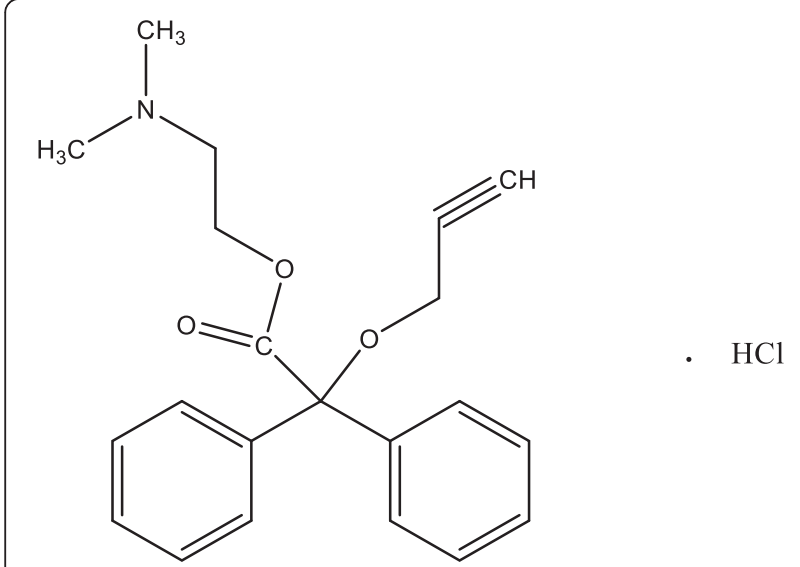

Fig. 2 Chemical structure of the internal standard pargeverine hydrochloride

\section{Methods}

\section{Chemicals and materials}

Carbinoxamine maleate and pargeverine hydrochloride standards were gifted by RL Fine Chemicals, Bengaluru, India. n-Hexane, 2-proponol, ethanol, and diethylamine were procured from Merck, Mumbai, India. Highperformance liquid chromatography (HPLC)-grade water was obtained from a Milli-Q unit (Millipore, Milford, USA). Blank human plasma was obtained from JSS Medical College and Hospital, JSS University, Mysuru, India.

\section{Instrumentation}

The instrumentation consisted of a Shimadzu Prominence LC-20 AD ultrafast liquid chromatography (UFLC) equipped with a 1260 binary pump VL (35 MPa), Prominence SIL-20ACHT Auto sampler, and Prominence SPD-M20A Diode array detector. All weighings for analysis were performed on a Shimadzu electronic analytical balance AY-220 (Shimadzu). Plasma samples were sonicated on a Mark ultrasonic sonicator and vertexed on a Remi cyclomixer; centrifugation was done using REMI centrifuge model number 412 LAG (REMI Instruments Division, Vasai, India). Water used for analysis was prepared from Millipak Express 20 filter unit. Microsoft Excel 2007 was used for analysis of validation results.

\section{Chromatographic conditions}

The chromatographic separations were carried out on amylose tris(5-chloro-2-methylphenylcarbamate) column. The mobile phase was a mixture of $n$-Hexane/isopropanolthanol/diethyl amine (850:75:75:0.1, $v / v / v / v)$ with $0.8 \mathrm{~mL} / \mathrm{min}$ of flow rate, and detection was performed by a photodiode array detector (PDA) at $220 \mathrm{~nm}$.

\section{Preparation of stock and standard solutions}

Stock solutions of CA and PGV in isopropanol were prepared separately at a concentration of $10 \mu \mathrm{g} / \mathrm{mL}$. A series of standard mixture solutions were prepared by the appropriate dilution of the stock standard solutions with isopropanol to a concentration range of 0.4$1000 \mu \mathrm{g} / \mathrm{mL}$ for CA and $40 \mu \mathrm{g} / \mathrm{mL}$ for PGV.

\section{Preparation of samples}

The plasma samples were thawed at room temperature. The samples were vortexed adequately before pipetting. To a $200-\mu \mathrm{L}$ aliquot of plasma, $100 \mu \mathrm{L}$ of racemic CA stock solution $(0.4-1000 \mu \mathrm{g} / \mathrm{mL}), 100 \mu \mathrm{L}$ of IS solution $(40 \mu \mathrm{g} / \mathrm{mL})$, and $100 \mu \mathrm{L}$ of $1 \mathrm{M} \mathrm{NaOH}$ were added and vortexed for $1 \mathrm{~min}$ in a 2 -mL Eppendorf tube. The mixed samples were then extracted with $1.5 \mathrm{~mL}$ of dichloromethane: n-Hexane (1:2), by vortex mixing for $2 \mathrm{~min}$. After centrifugation at $5000 \mathrm{rpm}$ for $15 \mathrm{~min}$, $1.0 \mathrm{~mL}$ of the upper organic layer was transferred to another tube. Extracts were concentrated to dryness at the $40{ }^{\circ} \mathrm{C}$ under a gentle stream of nitrogen and reconstituted with $150 \mu \mathrm{L}$ of ethanol. A $25-\mu \mathrm{L}$ aliquot of the solution was injected into the UFLC system for the analysis.

\section{Bio-analytical method validation \\ Calibration curve}

The plasma calibration curve was constructed using a blank sample (matrix sample processed without analyte or internal standard), a zero sample (matrix sample processed without analyte but with internal standard), and six non-zero samples (matrix samples processed with analyte and internal standard) covering the expected range including lower limit of quantification (LLOQ), 20-7500 ng/mL with $2000 \mathrm{ng} / \mathrm{mL}$ of IS concentration.

\section{Extraction recovery}

The efficiency of carbinoxamine enantiomers and IS extraction from human plasma was determined by comparing the responses of the analyte extracted from six reproduce QC samples with the response of analyte from neat standards at equivalent concentrations by a liquid-liquid extraction process. Recoveries of CA were determined at the LLOQ, QC low, QC medium, and QC high concentrations that is, 20,300, 1200, and $5000 \mathrm{ng} /$ $\mathrm{mL}$. Whereas the recovery of the IS was determined at a single concentration of $2000 \mathrm{ng} / \mathrm{mL}$.

\section{Accuracy and precision}

The intra-assay accuracy and precision were estimated by analyzing six replicates containing $\mathrm{CA}$ at four different QC levels, that is, 20, 300, 1200, and $5000 \mathrm{ng} / \mathrm{mL}$. The inter-assay precision was estimated by studying the quality control samples on four different runs. The criteria for acceptability of accuracy data within 85-115\% of the actual values and $\pm 15 \%$ relative standard deviation (RSD) except for LLOQ for precision. 


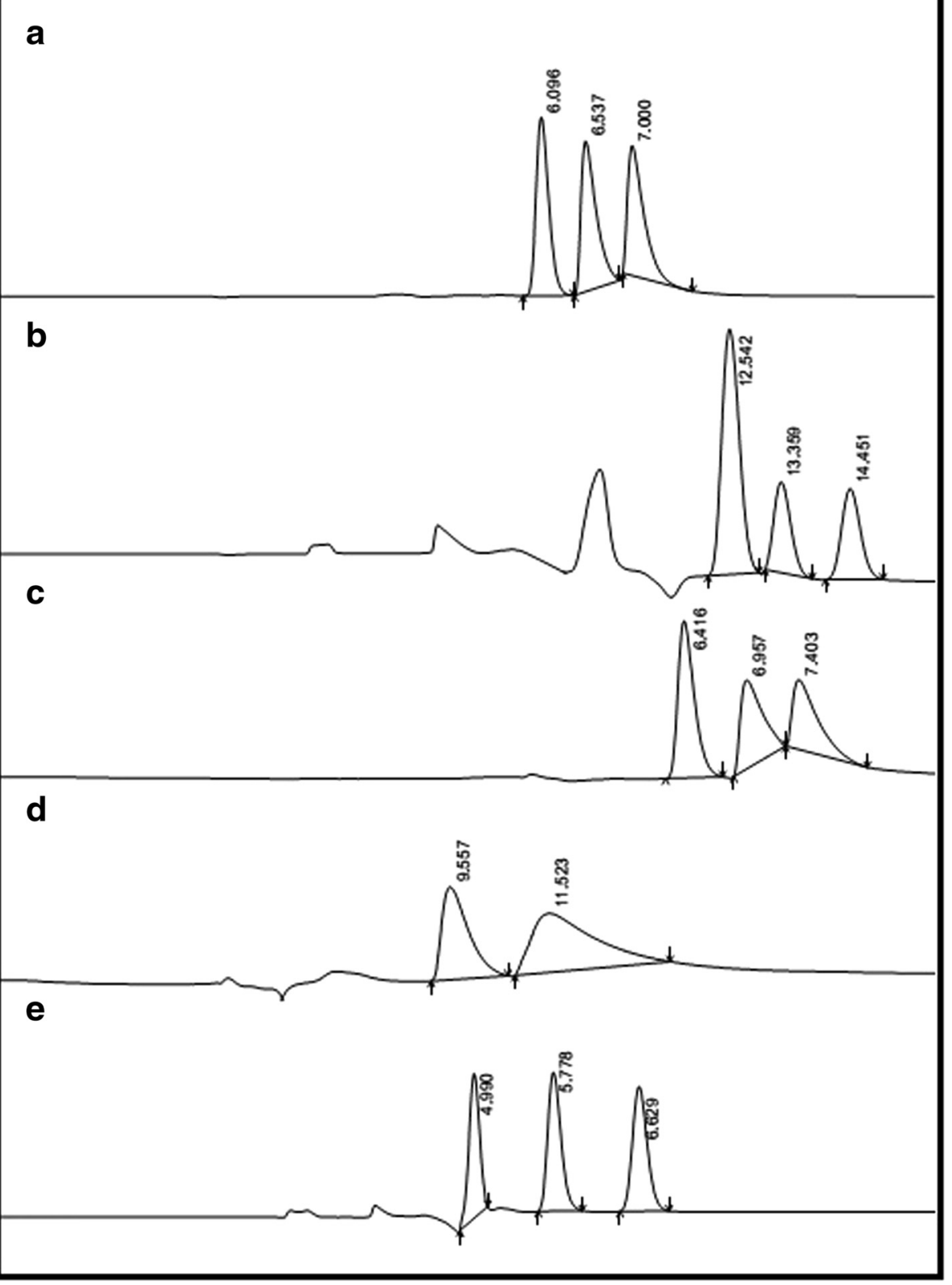

Fig. 3 Effect of organic modifiers on the resolution of CA enantiomers a methanol, b ethanol, c isopropanol, $\mathbf{d}$ n-butanol, e ethanol:isopropanol (1:1)

Table 2 Screening of alcoholic modifiers

\begin{tabular}{llll}
\hline Trail no. & Alcoholic modifiers & $\begin{array}{l}\text { Alcoholic modifier }(\mathrm{X}) \text { per } \\
100 \mathrm{~mL} \text { of mobile phase }(\mathrm{mL})\end{array}$ & Observations \\
\hline 1 & Methanol & 15 & Poor resolution between the enantiomers, tailing of peaks observed \\
2 & Ethanol & 15 & Enantiomers eluted very lately and the peak shape is broad. \\
3 & Isopropanol & 15 & Enantiomers eluted early but not separated completely; no resolution between the peaks. \\
4 & n-Butanol & 15 & No proper separation of enantiomers \\
5 & Ethanol:isoproponol & $7.5: 5$ & Enantiomers eluted early with good resolution and capacity factor. \\
\hline
\end{tabular}


Table 3 System suitability parameters

\begin{tabular}{lcllll}
\hline Name & $\begin{array}{l}\text { Retention } \\
\text { time } \\
\text { (tR)(min) }\end{array}$ & $\begin{array}{l}\text { Theoretical } \\
\text { plates }(M)\end{array}$ & $\begin{array}{l}\text { Tailing } \\
\text { factor ( }(T)\end{array}$ & $\begin{array}{l}\text { Resolution } \\
(\mathrm{Rs})\end{array}$ & $\begin{array}{l}\text { Capacity } \\
\text { factor }(K)\end{array}$ \\
\hline $\begin{array}{l}\text { Pargeverine } \\
\text { HCl (IS) }\end{array}$ & 4.9 & 3784 & 1.12 & - & - \\
(d)-form & 5.8 & 5387 & 1.38 & 3.95 & 1.15 \\
(I)-form & 6.79 & 5821 & 1.32 & 3.01 & 1.28 \\
\hline
\end{tabular}

\section{Stability experiments}

Stability tests were conducted to evaluate the stability of CA enantiomers in plasma samples under different conditions. In-injector stability $(24 \mathrm{~h})$, bench-top stability $(12 \mathrm{~h})$, freeze-thaw stability (3 cycles), and freezer stability $\left(80 \pm 10^{\circ} \mathrm{C}\right.$ for 25 days) were tested at LQC $(300 \mathrm{ng} / \mathrm{mL})$ and HQC (5000 ng/mL) levels using six replicates at each level. Samples were said to be stable if assay values were within the acceptable limits (i.e., 85-115\% accuracy and $\pm 15 \%$ RSD from fresh samples).

\section{Results and discussion}

Method development and optimization Selection of chiral stationary phase

The finest chiral stationary phases (CSP) for the separation of aromatic compounds with functional groups such as carbonyl, alcohol, and amine (like carbinoxamine) are amylose-based polysaccharide stationary phases (LCGC
2008). Immobilized polysaccharide columns are compatible with a wide range of solvents; hence, they can be operated in both reverse phase and normal phase which increased the range of applications (Othman et al. 2012). Hence, the coated amylose-based polysaccharide column was selected for screening.

The CSP is amylose tris(5-chloro-2-methylphenylcarbamate) bonded to silica gel. The separation of enantiomers may be attributed to hydrogen bonding interactions between the amine group of solute and the hydrophilic carbamate group on the CSP. Steadying effect on the solute-CSP complex will be there for the solutes having aromatic functional groups (Irving and Rose 1987). This type of steadying effect (or) stabilization effect may also exist in CA owing to the presence of aromaticity.

\section{Selection and optimization of additives}

As polysaccharide-based CSPs generally show a higher success rate in resolving enantiomers under normalphase elution (Brian 2010); hence, this mode was explored first. The selection of mobile phases was initiated with traditional alkane/alcohol mixtures (Chiral Technologies 2004). n-Hexane was given first preference as it is comparatively green (Paul et al. 2012). For separation of most of the analytes containing basic and/or acidic functional groups, the additive plays a major role in increasing the chromatographic efficiency (Zhang et al. 2012). The additives were used in the present word in

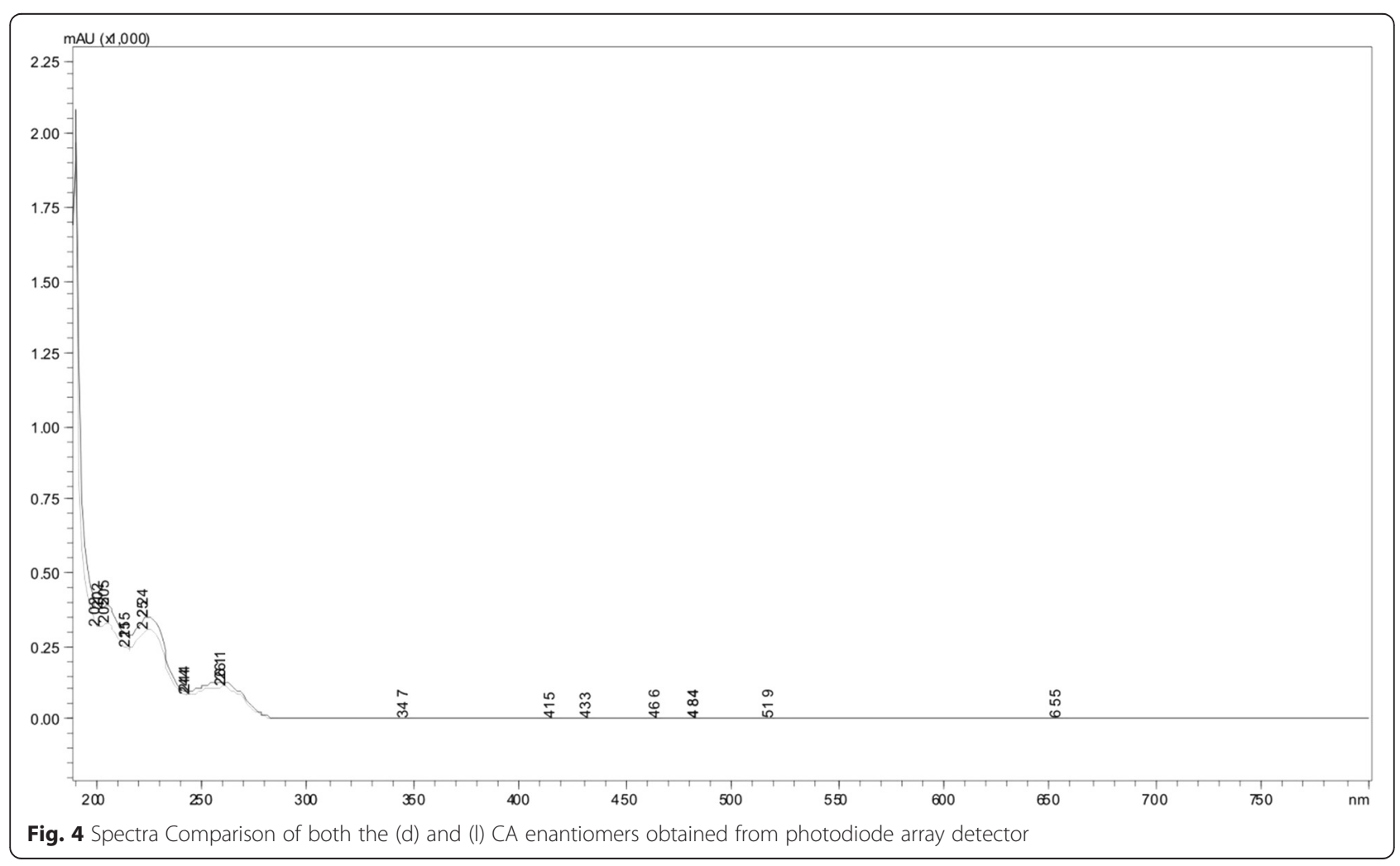




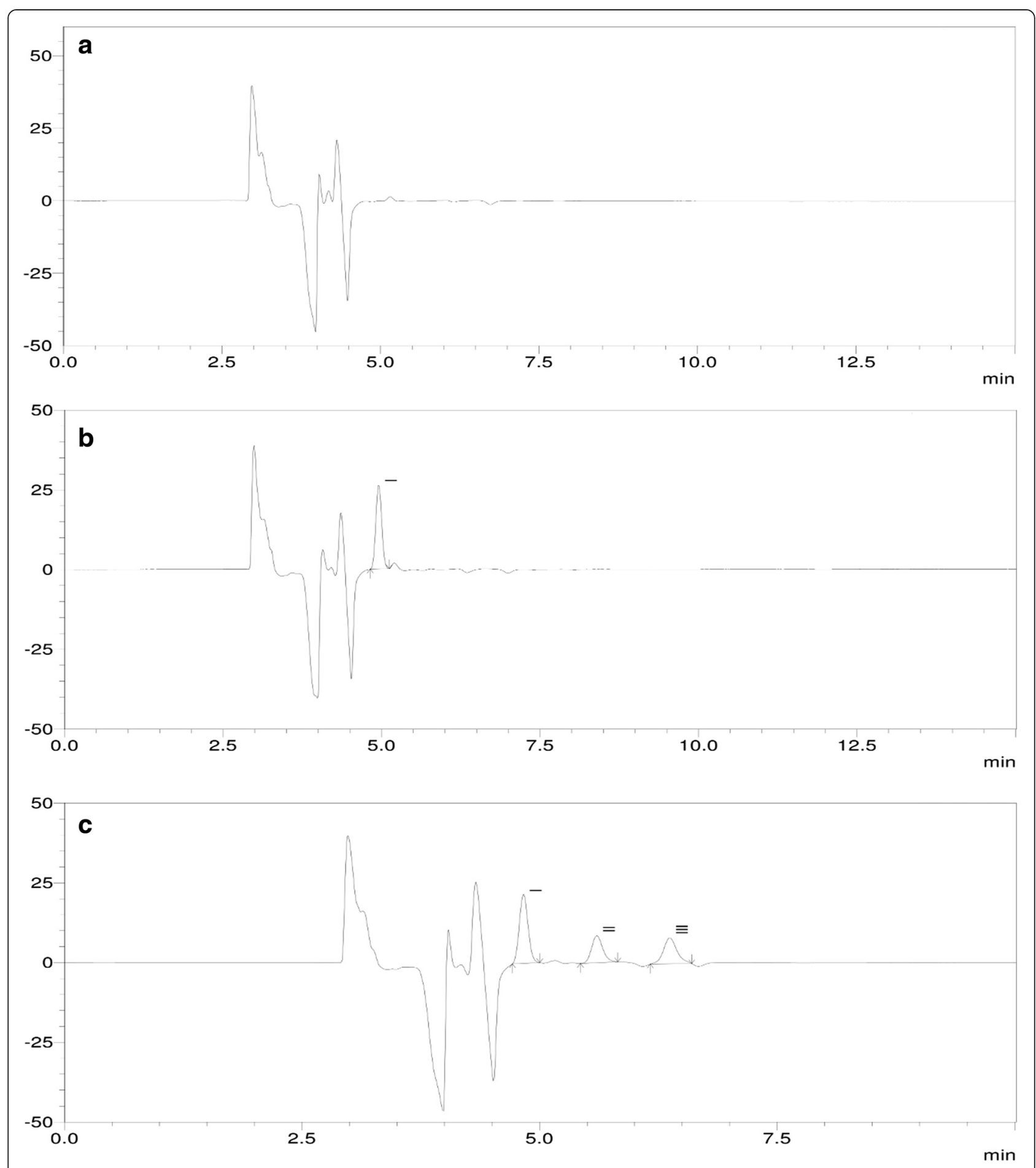

Fig. $5 \mathrm{HPLC}$ chromatograms of a $25 \mu \mathrm{L}$ injection containing pargeverine hydrochloride (I), (d)-form (II) and (I)-form (III) in a human blank plasma, b blank human plasma spiked with IS (zero sample), and c blank human plasma spiked with CA and IS (non-zero sample)

order to improve the peak shape. All chromatographic parameters were kept constant (flow rate, $0.8 \mathrm{~mL} / \mathrm{min}$, ambient column oven temperature; injection volume, $25 \mu \mathrm{L}$; wavelength, $220 \mathrm{~nm}$ ) except the \% additive added.
Diethylamine and triethylamine were often used as a modifier for basic drugs with amine groups to ensure elution from the column and to obtain good peak shape (Toussaint et al. 2000). Hence $0.01 \%$ diethylamine was 
Table 4 Recovery of Carbinoxamine enantiomers $(n=6)$

\begin{tabular}{lll}
\hline & \multicolumn{2}{l}{ Mean recovery $\% \pm S D$} \\
\cline { 2 - 3 } Quality control sample $(\mathrm{ng} / \mathrm{mL})$ & $(\mathrm{l})$-carbinoxamine & $(\mathrm{d})$-carbinoxamine \\
\hline LQC \pm 300 & $103.1 \pm 2$ & $101.7 \pm 7.60$ \\
MQC \pm 1200 & $94.4 \pm 3$ & $104.5 \pm 2.7$ \\
HQC \pm 5000 & $97.4 \pm 6$ & $94.1 \pm 8.9$ \\
\hline
\end{tabular}

introduced into the mobile phase, CA enantiomers were eluted at around $10 \mathrm{~min}$, and the peaks were highly asymmetric. Further increase in diethylamine content $(0.1 \%)$ has significant impact on the peak shape, whereas the mobile phase without diethylamine significantly distorted the peak shape.

\section{Selection of alcoholic modifiers}

In chiral separations, the alcohols play a major role in creating a selectivity difference (Tang 1996). Hence, the ratio of the mobile phase components n-Hexane/alcohol/diethylamine was fixed at 85:15:0.01 $(v / v / v)$ and the effect of different alcohols on selectivity was studied (Fig. 3). The details of different alcohols screened (trials 1-5) and their results are given in Table 2. The results of trials 3 and 4 appeared to be complementary. Ethanol alone as an alcoholic component in trial 2 produces broad peaks with slow elution. Isopropanol alone eluted the enantiomers very early, and because of which, the resolution is not proper. Hence, to achieve the complementary effects of trials 2 and 3, ethanol and isopropanol was tested together (trial 5). Since trial 5 showed a significant improvement in the retention and resolution, an equal ratio of ethanol and isopropanol were used for the analysis. Hence, at the optimized chromatographic conditions, the internal standard and the enantiomers were eluted at 4.9, 5.8, and 6.79 min, respectively, passing all the chromatographic parameters (Table 3).

\section{Optical rotation of $\mathrm{CA}$ enantiomers}

The order of elution of ('d') or (+) and ('l') or (-) CA enantiomers was determined by collecting eluent fractions from repeated injections (Dalia et al. 2008). There were $\sim 45$ injections made into the UFLC, with $150 \mu \mathrm{g}$ racemate per injection. Figure 4 depicts the spectral comparison of both the enantiomers, which shows that both the peaks represent the same drug. After compiling the eluent fractions corresponding to each enantiomer, they were dried by passing the nitrogen gas and reconstituted in methanol and the optical rotation was determined using a Jasco P-2000 (JASCO Analytical instruments, USA).

\section{Assay validation}

The bio-analytical validation was performed according to FDA guidelines (FDA guideline 2001).

\section{Calibration curve}

The calibration standard curve had a reliable reproducibility over the standard concentrations across the calibration range. The calibration curve was constructed by determining the best fit of peak area ratios (peak area analyte/peak area IS) vs. concentration and fitted to the $y=m x+c$. The average regression $(n=3)$ was found to be $\geq 0.996$ for both the (d) and (l) enantiomers of CA. The lowest concentration with the RSD $<20 \%$ was taken as the LLOQ and was found to be $20 \mathrm{ng} / \mathrm{mL}$.

\section{Extraction recovery}

One-step liquid-liquid extraction technique gave adequate recovery and cleaner samples (Fig. 5). The results of the comparison of neat standards vs. human plasmaextracted standards were estimated for CA enantiomers at low (300 ng/mL), medium (1200 ng/mL), and high

Table 5 Intra- and inter-day precision of determination of CA in human plasma

\begin{tabular}{|c|c|c|c|c|c|c|}
\hline \multirow{3}{*}{$\begin{array}{l}\text { Theoretical concentration } \\
(\mathrm{ng} / \mathrm{mL})\end{array}$} & \multicolumn{6}{|c|}{ Measured concentration (ng/mL), $(n=6)$} \\
\hline & \multicolumn{2}{|l|}{ Mean \pm SD } & \multicolumn{2}{|l|}{ RSD } & \multicolumn{2}{|c|}{ Accuracy (\%) } \\
\hline & (d)-form & (I)-form & (d)-form & $(\mathrm{l})$-form & (d)-form & (I)-form \\
\hline \multicolumn{7}{|l|}{ Intra-day variation } \\
\hline 20 & $20.1 \pm 0.85$ & $19.4 \pm 0.35$ & 4.2 & 1.8 & 102 & 97 \\
\hline 300 & $320 \pm 5.28$ & $307 \pm 6.35$ & 1.65 & 2.06 & 107 & 102 \\
\hline 1200 & $1228 \pm 10.4$ & $1261 \pm 9.37$ & 0.84 & 0.74 & 102 & 105 \\
\hline 5000 & $4734 \pm 24.5$ & $4675 \pm 20.15$ & 0.51 & 0.43 & 95 & 94 \\
\hline \multicolumn{7}{|l|}{ Inter-day variation } \\
\hline 20 & $20.5 \pm 0.17$ & $20.6 \pm 0.74$ & 0.82 & 3.5 & 103 & 103 \\
\hline 300 & $314 \pm 2.38$ & $324 \pm 7.12$ & 0.75 & 2.19 & 105 & 108 \\
\hline 1200 & $1274 \pm 11.3$ & $1257 \pm 18.74$ & 0.88 & 1.49 & 106 & 105 \\
\hline 5000 & $4735 \pm 70.1$ & $4823 \pm 88.45$ & 1.48 & 1.83 & 95 & 96 \\
\hline
\end{tabular}


Table 6 Stability data CA quality controls in human plasma

\begin{tabular}{|c|c|c|c|c|c|c|c|}
\hline \multirow{2}{*}{$\begin{array}{l}\text { Nominal con. } \\
(\mathrm{ng} / \mathrm{mL})\end{array}$} & \multirow[t]{2}{*}{ Stability } & \multicolumn{2}{|l|}{ Mean \pm SD } & \multicolumn{2}{|c|}{ Accuracy (\%) } & \multicolumn{2}{|c|}{ Precision (\% CV) } \\
\hline & & (d)-form & (I)-form & (d)-form & (I)-form & (d)-form & (l)-form \\
\hline \multirow[t]{5}{*}{300} & $\mathrm{Oh}$ & $317 \pm 9.07$ & $286 \pm 8.34$ & 106 & 95 & 2.86 & 2.91 \\
\hline & $12 \mathrm{~h}$ (bench-top) & $323 \pm 5.01$ & $257 \pm 2.76$ & 108 & 86 & 1.55 & 1.07 \\
\hline & 24 h (in-injector) & $326 \pm 9.72$ & $317 \pm 5.2$ & 109 & 106 & 2.98 & 1.64 \\
\hline & Freeze-thaw & $340 \pm 12$ & $296 \pm 10$ & 113 & 99 & 3.52 & 3.4 \\
\hline & 25 days at $-80^{\circ} \mathrm{C}$ & $338 \pm 1.47$ & $318 \pm 3.4$ & 113 & 106 & 0.43 & 1.0 \\
\hline \multirow[t]{5}{*}{5000} & $\mathrm{Oh}$ & $4681 \pm 54.3$ & $4478 \pm 28.9$ & 93 & 90 & 1.16 & 0.64 \\
\hline & $12 \mathrm{~h}$ (bench-top) & $4734 \pm 47.4$ & $5183 \pm 38.5$ & 95 & 104 & 1 & 0.74 \\
\hline & $24 \mathrm{~h}$ (in-injector) & $4697 \pm 35.1$ & $5013 \pm 60.7$ & 94 & 100 & 0.74 & 1.21 \\
\hline & Freeze-thaw & $4737 \pm 70.2$ & $4826 \pm 51.2$ & 95 & 97 & 1.48 & 1.05 \\
\hline & 25 days at $-80^{\circ} \mathrm{C}$ & $4705 \pm 35.4$ & $4478 \pm 32.7$ & 94 & 90 & 0.76 & 0.73 \\
\hline
\end{tabular}

(5000 ng/mL) levels, and the mean recovery for (d) and (l) enantiomers of CA was shown in Table 4. The recovery of internal standard $(2000 \mathrm{ng} / \mathrm{mL})$ was $96.35 \%$.

\section{Accuracy and precision}

The results of accuracy and precision throughout the standard curve for (d) and (l) enantiomers of CA are presented in Table 5. The RSD values of intra-day and inter-day precision for two enantiomers were less than $4.2 \%$. All the values of accuracy and precision including the LLOQ fell within the limits which were considered as acceptable.

\section{Stability studies}

The concentrations of CA at low $(300 \mathrm{ng} / \mathrm{mL})$ and high (5000 $\mathrm{ng} / \mathrm{mL}$ ) level samples deviated within $\pm 15 \%$ of the nominal concentrations in stability tests like in-injector $(24 \mathrm{~h})$, bench-top $(12 \mathrm{~h})$, three repeated freeze-thaw cycles, and freezer stability $\left(-80 \pm 10{ }^{\circ} \mathrm{C}\right.$ for 25 days $)$ (Table 6). The results were found to be within the assay variability limits during the entire process.

\section{Conclusions}

The developed method was found to be sensitive, specific, and robust for quantification of both the (d) and (l) enantiomers of carbinoxamine in human plasma. The method involved sample preparation with adequate recovery by liquid-liquid extraction. Method parameters like \% alcoholic modifier, \% basic additive, and flow rate were successfully adjusted. The method ensured as a robust one from the responses obtained. Even for injection volume $25 \mu \mathrm{L}$ the method is quite sensitive. The method is userfriendly because of using green solvents $n$-Hexane and ethanol. It is concluded that the method is suitable for the routine quantification of (d) and (l) enantiomers of CA in human plasma.

\section{Competing interests}

The authors declare that they have no competing interests.

\section{Authors' contributions}

ST has carried out the major research work presented in this article. BMG, acted as guide for research work and helped in giving the inputs for various topics carried out in this research work. BKl, helped in preparing and drafting the manuscript

\section{Acknowledgements}

Authors are thankful to The Principal, JSS College of Pharmacy, JSS University, Mysuru, India for providing the necessary facilities. The authors express gratitude to Dr. Ramesh A. R, Vice President, R L Fine Chem, Bengaluru, for providing the racemic carbinoxamine maleate drug as a gift sample. Authors are beholden to University Grants Commission, New Delhi for the financial assistance (Ref: F.No.40-271/2011 (SR) dated 10.01.2013).

Received: 1 June 2015 Accepted: 3 November 2015

Published online: 10 November 2015

\section{References}

Abdul AR, Hasna M, Taha G. Determination of carbinoxamine maleate in pharmaceuticals by direct and differential pulse polarography. Asian J Chem. 2009:21(9):7387-97.

Brian LH. In: Alain B, editor. Chiral recognition in separation methods: mechanisms and applications. New York: Springer; 2010.

Casy AF, Drake AF, Ganellin CR, Mercer AD, Upton C. Stereochemical studies of chiral $\mathrm{H}-1$ antagonists of histamine: the resolution, chiral analysis, and biological evaluation of four antipodal pairs. Chirality. 1992;4:356-66.

Chiral Technologies Europe (2004). Instruction manual for Chiralpak-IA column. http://www.ctk.com/layouts/default/image/files/bak/CHIRALPAK-IA.pdf

Dalia AH, Dion R, Brocks A. Stereospecific high-performance liquid chromatographic assay for the determination of ketoconazoleenantiomers in rat plasma. Biomed Chromatogr. 2008;22:542-7.

de Carina AB, Marcone ALD. Quantitative determination of acetaminophen, phenylephrine and carbinoxamine in tablets by high-performance liquid chromatography. Quím Nova. 2009;32(7):1951-5.

FDA guideline (2001). Guidance for industry: bioanalytical method validation, US, FDA. Rockville, MD.

GeetaBhavani B, Gurupadayya BM, Sharfuddin S. LC-MS/MS method for the quantification of carbinoxamine in human plasma. IOSR J Appl Chem. 2014;6:46-51.

Irving WW, Rose MS. Resolution of enantiomeric aromatic alcohols on a cellulose tribenzoate high-performance liquid chromatography chiral stationary phase: a proposed chiral recognition mechanism. J Chromatogr A. 1987;411:139-51.

Ismail MP, Feyyaz O. Simultaneous spectrophotometric and liquid chromatographic determination of dextromethorphanhydrobromide, phenylephrine hydrochloride, and carbinoxamine maleate in pharmaceutical preparations. J Anal Chem. 2012;67(1):56-63. 
LCGC (2008). A strategy for developing HPLC methods for chiral drugs. http://www.chromatographyonline.com/lcgc/data/articlestandard/lcgc/ 122008/504160/article.pdf

Michael P, Kalyn S, Maegan Z, David BG (2008). Quantitative determination of carbinoxamine, dextromethorphan and pseudoephedrine in human plasma by LC/MS/MS. Available via http://www.chromatographyonline.com/strategydevelopinghplc-methods-chiral-drugs-1

Othman Z, Ali I, Asim M, Khan TA. Recent trends in chiral separations on immobilized polysaccharides CSPs. Comb Chem High Throughput Screen. 2012;15(4):339-46.

Paul F, Mark H, Jennifer Y. In: Wei Z, Berkeley C, editors. Green techniques for organic synthesis and medicinal chemistry. West Sussex: Wiley; 2012.

Pharma Book Syndicate (2009). http://www.pharmabooksyndicate.com/issues/309.pdf

Phenomenex (2013). http://phx.phenomenex.com/lib/BR98701212_I.pdf

Ramadan AA, Mandil H. Spectrophotometric determination of carbinoxaminemaleate in pharmaceutical formulations by ternary complex formation with Cu (II) and eosin. Anal Biochem. 2006;353(1):133-7.

River's Edge Pharmaceuticals (2011). http://dailymed.nlm.nih.gov/dailymed/archives/ bfdaDruglnfo.cfm?archiveid $=68514$

Tadiboyina S, Gurupadayya B, Inturi B (2015). Chiral separation of (d)- and (I)enantiomers of doxylamine succinate in rat plasma. Bulletin of Faculty of Pharmacy, Cairo University. Available online 16 May 2015.

Tang Y. Significance of mobile phase composition in enantioseparation of chiral drugs by HPLC on a cellulose-based chiral stationary phase. Chirality. 1996;8:136-42.

Toussaint B, Duchateau AL, Vanderwal S, Albert A, Hubert P, Crommen J. Determination of the enantiomers of 3-tertbutylamino- 1,2-propanediol by high-performance liquid chromatography coupled to evaporative light scattering detection. J Chromatogr A. 2000;890:239-49.

USP29-NF24 (2007). http://www.pharmacopeia.cn/v29240/usp29nf24s0_ m12920.html

Yi-Fen T, Hsin-Lung W, Shou-Mei W, Su-Hwei C, Hwang-Shang K. Quantitative chiral analysis of carbinoxamine, doxylamine, and orphenadrine by capillary zone electrophoresis. J Microcolumn Sep. 2000;12:366-70.

Zhang T, Franco P, Nguyen D, Hamasaki R, Miyamoto S, Ohnishi A, et al. Complementary enantiorecognition patterns and specific method optimization aspects on immobilized polysaccharide-derived chiral stationary phases. US Food and Drug Administration: J Chromatogr A. 2012;1269:178-88. http://www.fda.gov/downloads/Drugs/../Guidances/ucm070107.pdf

\section{Submit your manuscript to a SpringerOpen ${ }^{\circ}$ journal and benefit from:}

- Convenient online submission

- Rigorous peer review

- Immediate publication on acceptance

- Open access: articles freely available online

- High visibility within the field

- Retaining the copyright to your article

Submit your next manuscript at $\gg$ springeropen.com 